\title{
Low pressure water-mist nozzle with a swirl worm screw inserts
}

\author{
Nadezhda Kropotova ${ }^{1,},{ }^{*}$, Alexander Arakcheev ${ }^{1}$, Leonid Tanklevskiy ${ }^{1}$, Anton Tanklevskiy ${ }^{1}$ \\ ${ }^{1}$ Peter the Great St. Petersburg Polytechnic University, 195251, 29 Politekhnicheskaya Street, St. \\ Petersburg, Russia
}

\begin{abstract}
The article contains the main results of the creation of a nozzle of improved design research work. To improve application efficiency of low-pressure nozzle of water mist in automatic fire-extinguishing system (AFS), the construction of centrifugal nozzles with swirl worm screw inserts was changed. The construction features of this sprayer, methods of its testing and obtained results these tests characteristics are presented.
\end{abstract}

\section{Introduction}

Nowadays the protection of people is a difficult task which involves a wide range of issues. Safety management models are also important, in particular, making the right management decisions, predict damage assessment, reliability calculation and much more. [1-10] Many modern scientific research works has included investigations about the reliability and strength of building materials. [11-12] Fire protection methods, which are divided into active and passive, are important [13-20] In this article we considered the elements of automatic fire protection system.

Traditional water fire-extinguishing systems installations have a drawback - they have a low efficiency of using a fire-extinguishing agent (hereinafter-FA). Also, the amount of water consumed in extinguishing a fire can cause significant material damage.

In work of Meshman L. M., R. Y. Gubin, A. G. Didaev, Tanklevskiy L. T., A. L. Tanklevskiy there is information about the effectiveness, quality criteria and functions carried out by AFS.[21]

High efficiency in firefighting in small rooms have low pressure sprayers (hereinafter LP) water mist (hereinafter - WM). WM has a high penetration and a large cooling ability, ensures the reliable suppression of fires using small amount of FA. Also, extinguishing with the help of WM reduces the damage from extinguishing fires, is more environmentally friendly compared to methods of extinguishing using other FA.

A different approach to the organization of the processes of motion and interaction of liquid jets [20] allows to develop different types of sprayers.

Our research team has developed a new construction of nozzle with a swirl worm screw inserts. This element of the sprayer is reliable in use in the presence of mechanical

*Corresponding author's email: $\underline{\text { doglee@ mail.ru }}$ 
impurities and salts in the water, capable of deposition in the elements of the nozzle, as well as the sprayer itself is easy to operate, it is possible to replace worn parts. Previously, the use of a swirl worm screw inserts in nozzles WM LP almost never realized, and there was no explanation of how to get the area of irrigation nozzle WM LP, close to the square.

We researched also the effect of construction changes of nozzle WM LP with a swirl worm screw inserts on the effectiveness of its application.

\section{Methods}

Atomizer a new construction with an alphanumeric designation of DUOZZ-ZHNGo/...KU2 V32 according to GOST P 51043-2002 [23] (working title of "the Fog") is intended for water mist irrigation on the protected area and is used in extinguishing or containment of fire, creating water curtains, cooling and process equipment (is shown in Fig. 1).

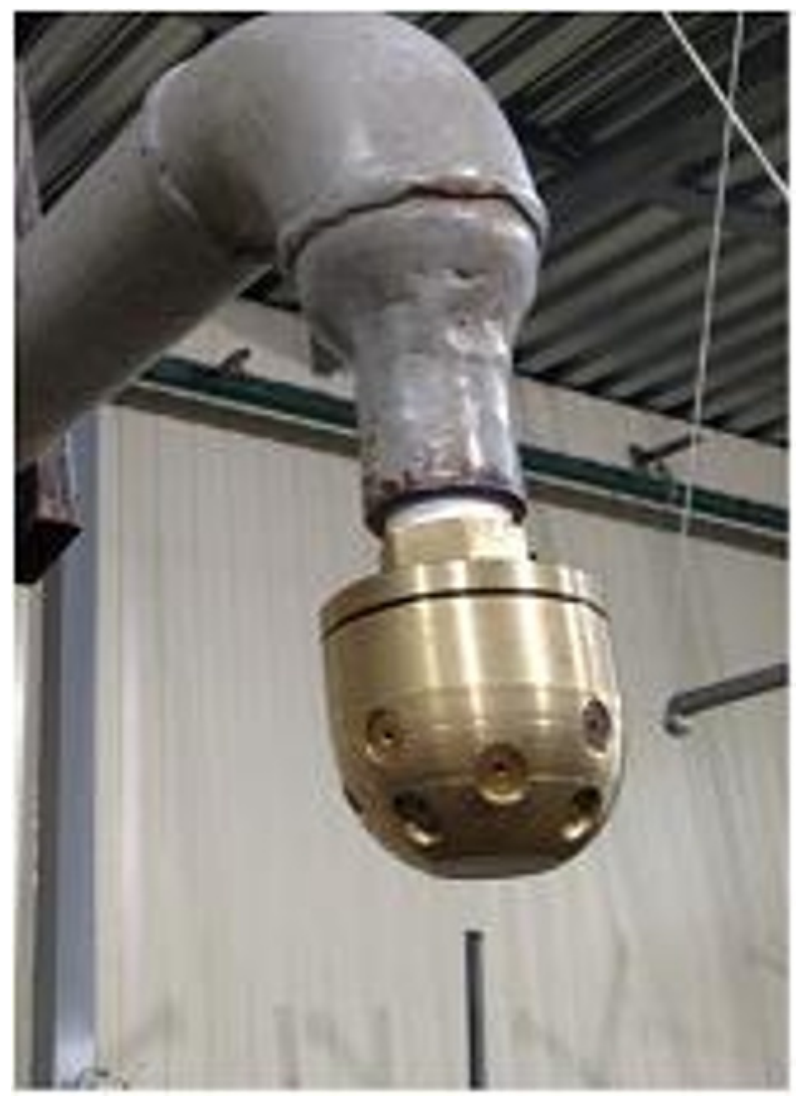

Fig. 1. Nozzle of new construction «The Fog».

Construction of experimental nozzle is shown in fig. 2. 


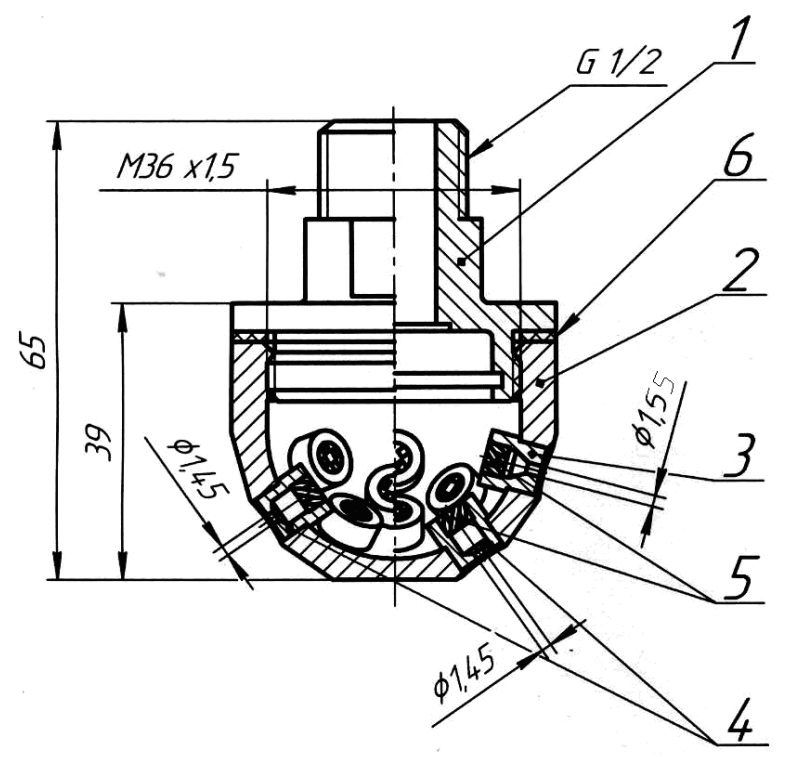

Fig. 2. Construction of experimental nozzle

( 1 - main body; 2 - spraying device; 3 - screw liner; 4 - cover; 5 - filter; 6 - outlet $)$

The construction of the nozzle (a) and the liner (b) of the swirl worm screw inserts are shown in fig. 3.

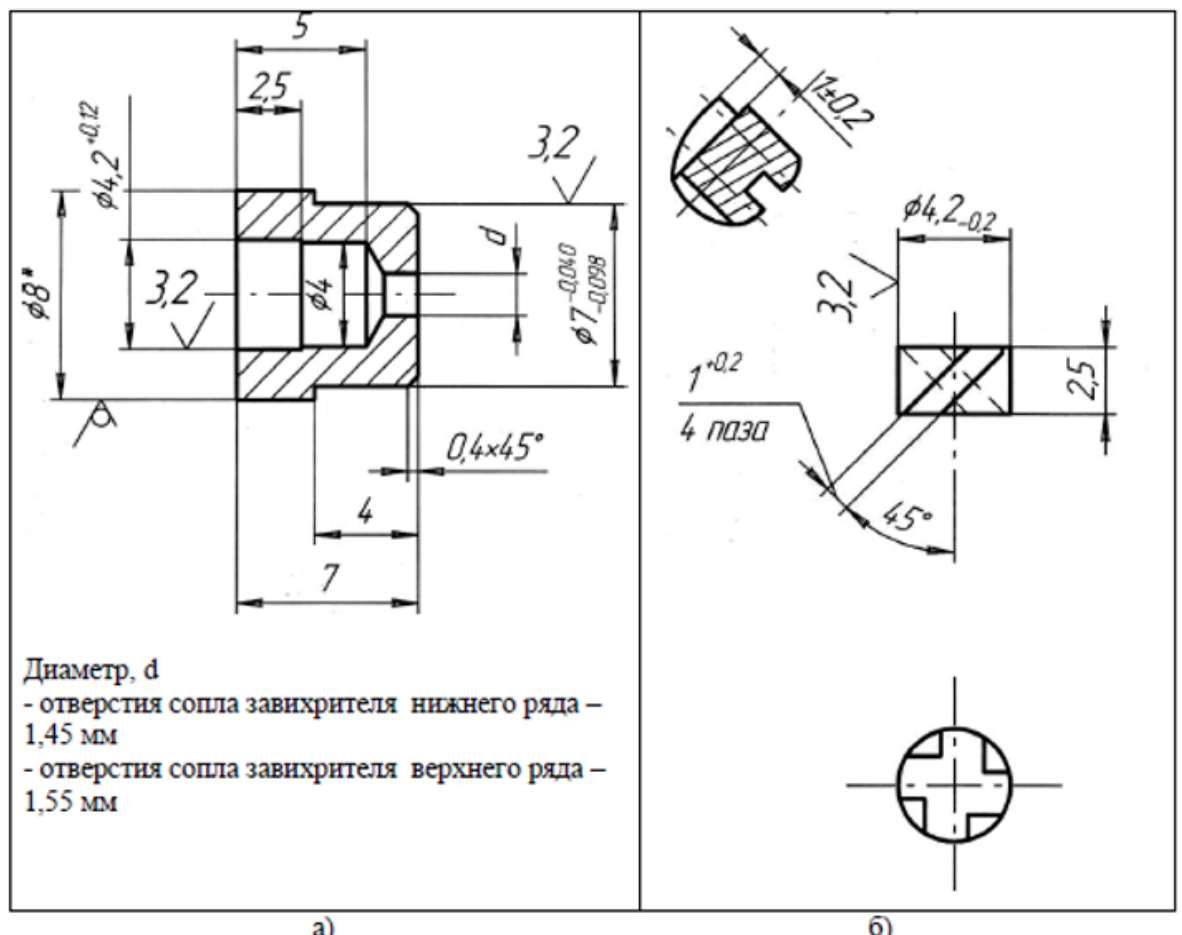

a)

б)

Fig. 3. The construction of the nozzle (a) and the liner (b) of the a swirl worm screw inserts. 
The construction of the nozzle is centrifugal with swirl worm screw inserts and 12 outlet hole in it. The diameter of the 8 holes of the nozzle swirler of the lower row is 1.45 $\mathrm{mm}$, the diameter of 4 holes of the upper row is $1.55 \mathrm{~mm}$.

Nowadays certification of nozzle contains tests the sprayer for the protected area, the uniformity, intensity of irrigation according to GOST R 51043-2002 [23], and R 50680-94 [24] (referring to "blind spots" where the action is ineffective [25]). In accordance with paragraph 8.23 GOST R 51043-2002 low pressure nozzle of water mist DUOZZ$\mathrm{ZHNGo} / . . .-\mathrm{KU} 2 \mathrm{~V} 32$ was tested. Measuring jars (size is $250 \mathrm{x} 250 \mathrm{~mm}$ and a height is 150 $\mathrm{mm})$ were installed in a checkerboard sequence.

These tests were carried out at the test range of Group of Companies Gefest. The sprayer was installed at a height of $2.5 \mathrm{~m}$ from the upper cut of the measuring jars. One of the 4 holes of the sprayer with a diameter of $1.55 \mathrm{~mm}$ was oriented along the diagonal of the square on which the measuring jars were installed (fig. 4).

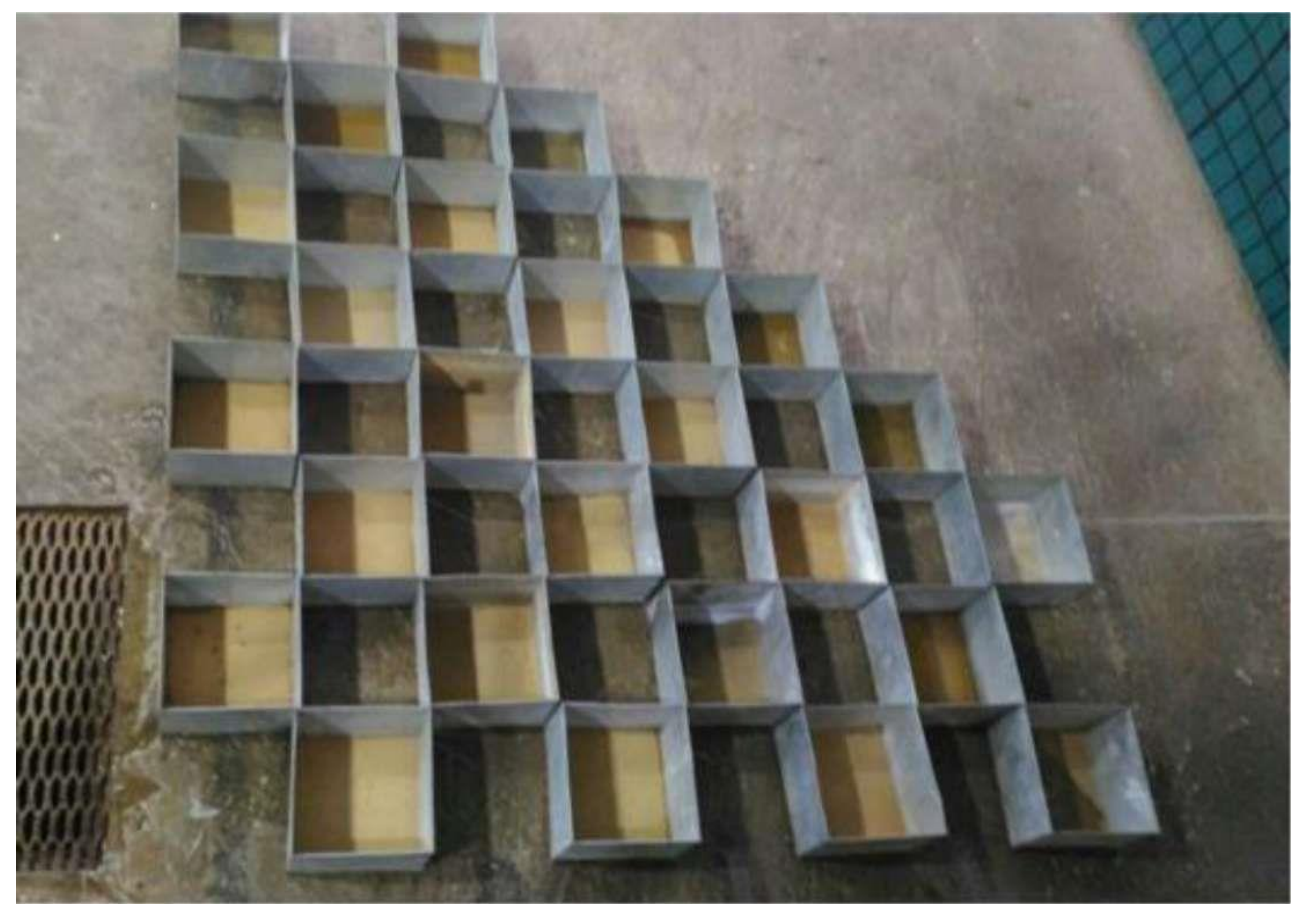

Fig. 4. Location measuring jars at the test range during the testing of the water nozzle.

This arrangement is explained by the fact that the nozzle forms a square-like shape of the irrigation area and has two rows of holes. The bottom row consists of 8 holes with a diameter of $1.45 \mathrm{~mm}$ and the upper row consists of the 4 holes with a diameter of $1.55 \mathrm{~mm}$, directed along the diagonal of the square. During the test, the water supply from the pipeline was carried out at a pressure of $0.5 ; 0.7 ; 0.9 ; 1.1 \mathrm{MPa}$. The duration of water supply was $180 \mathrm{sec}$.

Average irrigation intensity $\mathrm{I}, \mathrm{dm}^{3} /\left(\mathrm{m}^{2 *} \mathrm{sec}\right)$, was calculated by the following formula:

$$
I=\frac{\sum_{i=1}^{n} i_{i}}{n}
$$

where $i_{i}$ is intensity of irrigation in the $i$-th dimensional jar, $\mathrm{dm}^{3} /\left(\mathrm{m}^{3 *} \mathrm{sec}\right) ; n$ is the amount of dimensional jars, placed on the protected area. 
The intensity of irrigation in the $i$-th dimensional jar $i_{i}, \mathrm{dm}^{3} /\left(\mathrm{m}^{3 *} \mathrm{sec}\right)$, was calculated by the following formula:

$$
i_{i}=\frac{V_{i}}{0,0625 t}
$$

where $V_{i}$ is volume of water, collected in the $i$-th dimensional jar, $\mathrm{dm}^{3} ; t$ is time of irrigation, sec.

The uniformity of irrigation $S, \mathrm{dm}^{3} /\left(\mathrm{m}^{2 *} \mathrm{sec}\right)$, was calculated by the following formula:

$$
S=\sqrt{\frac{\sum_{i=1}^{n} i_{i}^{2}-\frac{\left(\sum_{i=1}^{n} i_{i}\right)^{2}}{n}}{n-1}},
$$

The coefficient of uniformity of irrigation $\mathrm{R}$ was calculated by the following formula:

$$
R=\frac{S}{i_{\mathrm{cp}}}
$$

The nozzle was considered to with stand the test with an average irrigation intensity above the norm and an irrigation uniformity coefficient of less than 0.5. At the same time, the number of measuring jars with irrigation intensity of not more than $50 \%$ of the norm does not exceed two. [23]

During the testing the mounting position of nozzle "Fog" was low. After the end of the sprayer spillage an irrigation plot was created, where data on the amount of water in each of the measuring jars were shown. According to the results of the experiments a protocol of hydraulic testing of the sprayer was drawn up. Then the analysis of data and construction of irrigation maps were carried out.

\section{Results}

According to the results of the first series of tests sprayer "The Fog" at a pressure of $0.5-1.1$ MPa irrigated the area to $5.3 \mathrm{~m}^{2}$. The shape of the irrigation zone is not similar to the square, the angle of the expected square of the irrigation zone is rounded. The obtained parameters did not satisfy the required area and form of irrigation. [23]

The increasing diameter of thetop 4 holes of the nozzle"The Fog" from $1.55 \mathrm{~mm}$ to 1.7 $\mathrm{mm}$ caused an increase in the irrigation area from 5.3 to $7.3 \mathrm{~m}^{2}$ and the shape of the irrigation area looked like the square. The coefficient of performance with increasing hole diameter increased and was in the range from 0.59 to 0.071 .

Consequently, it was concluded that the main advantages of the drencher mist sprayer with a diameter of the upper 4 holes of $1.7 \mathrm{~mm}$ are the following: spraying of water mist is no more than 100 microns; a homogeneous torch with a spray angle of up to 800 have the shape of the irrigation like the square; there are no "blind zones" during the extinguishing; there is homogeneous dispersion in the quenching zone; there is the ability to extinguish areas up to $7.3 \mathrm{~m}^{2}$ at a pressure of $0.7-1.1 \mathrm{MPa}$; there is no need to clean the excess spilled water.

Fire tests have also shown that the sprayer can only be used to extinguish solid fuel materials, but not for flammable liquid.

\section{Conclusions}

The research had the following results. 
1. Nozzle WM LP with a swirl worm screw inserts (8 holes which have a diameter of $1.45 \mathrm{~mm}$; 4 holes of the upper row have a diameter of $1.7 \mathrm{~mm}$ ) with square-like shape of irrigation was developed and used by the first time.

2. It is shown that with the diameter of the swirler of the nozzle increasing, its characteristics (protected area, irrigation intensity, productivity, etc.) are improving.

3. Fire tests allowed us to assert that the sprayer of this construction can only be used to extinguish class A fires and requires further development to increase the scope of application.

\section{References}

1. E.P. Istomin, V.M Abramov, V.G. Burlov, A.G. Sokolov, N.N. Popov, J. Int. Multidisciplinary Scient. GeoConference SGEM, 17 (21), 859866, (2017), doi: 10.5593/sgem2017/21/S08.109

2. V.G. Burlov, M.I. Grachev, N.S. Shlygina, Proceedings of 2017 20th IEEE International Conference on Soft Computing and Measurements, SCM 2017, Saint-Petersburg (2017)

3. V.G. Burlov, M.I. Grachev, Transp. Res. Procedia, 20, 100-106, (2017), doi: 10.1016/j.trpro.2017.01.02

4. V. Burlov, O. Lepeshkin, Transp. Res. Procedia, 20, 94-99, (2017), doi: 10.1016/j.trpro.2017.01.02

5. A. Tumanov, V. Gumenyuk, V. Tumanov, IOP Conf. Ser.: Earth Environ. Sci., 90(1), 012027 (2017), doi: 10.1088/17551315/90/1/012027

6. G. Korshunov, S. Polyakov, L. Shunmin, IOP Conf. Ser.: Earth Environ. Sci., 87(6), 062009 (2017), doi: 10.1088/1755-1315/87/6/062009

7. S.V. Efremov, O.V. Romantsova, V.B. Ulybin, J. Acta Astronautica, 150, 172-176, (2018), doi: 10.1016/j.actaastro.2018.01.018

8. V.A. Rybakov, I.A. Ananeva, A.O. Rodicheva, O.T. Ogidan, Magazine of Civil Engineering, 74 (6), 161-174, (2017), doi: 10.18720/MCE.74.13

9. A.I Kopylova, Alfabuild, 2(2), 18-22 (2017)

10. A.E. Radchenko, M.V. Petrochenko, Proceedings of the 2nd International Conference on Engineering Sciences and Technologies, ESaT, 2(1), 617-622, (2016)

11.S.V. Klyuev, A.V. Klyuev, A.D. Abakarov, E.S. Shorstova, N.G. Gafarova, Magazine of Civil Engineering, 75, 66-75 (2017), doi:10.18720/MCE.75.6

12. T.S. Shepelenko, N.P. Gorlenko, O.A. Zubkova, Magazine of Civil Engineering, 81, 125-134 (2018), doi:10.18720/MCE.81.13

13. L. Mesman, E. Romanova, R. Gubin, Fire safety journal, 2(2), 115-125, (2018)

14. V. Oreshina, E. Arkhipov, N. Borodin, Fire safety journal, 2(2), 126-135, (2018) 
15. V. I. Golovanov, V. V. Pavlov, A. V. Bahatikov, V. N. Bresin, T. V. Shkotova, Fire safety journal, 2(2), 17-25, (2018)

16. O. Zybina, M. Gravit, Y. Stein, IOP Conf. Ser.: Earth Environ. Sci., 90 (1), 012227 (2017), doi: 10.1088/1755-1315/90/1/012227

17. E.S. Burlakov, G.A. Evdokunin, A.S. Karpov, Proceedings of the 2017 IEEE Russia Section Young Researchers in Electrical and Electronic Engineering Conference, ElConRus, 7910543, 260-264, (2017)

18. I. Bolodian, A. Melikhov, L. Tanklevskiy, J. ActaAstronautica, 135, 100-108 (2017), DOI: 10.1016/j.actaastro.2016.10.002

19. L. Tanklevskiy, A. Tsoy, A. Snegirev, Fire Safety Journal, 91, 614623, (2017), DOI: 10.1016/j.firesaf.2017.04.019

20. I.V. Susoeva, T.N. Vahnina, A.A. Titunin, J.A. Asatkina, Magazine of Civil Engineering, 71, 39-50 (2017), doi:10.18720/MCE.71.5

21. L.M. Meshman, R.Y. Gubin, A.G. Dadaev, L.T. Tanklevskiy, A.L. Tankevskiy, Fire and exploding safety, 25(2), 28-50 (2016).

22. A. A. Grunin, A. V. Gurov, Collection of articles on the materials of the all-Russian scientific-practical conference with international participation 18 APR. 2014, Voronezh Institute of state fire service of EMERCOM of Russia, Voronezh, (2014).

23. GOST R 51043-2002. Water and foam fire extinguishing installations are automatic. Sprinklers. General technical requirements. Test method, Moscow (2002).

24. GOST $R$ 50680-94. Water fire extinguishing installations are automatic. General technical requirements. Test method, Moscow (1994).

25. GOST 15150-69. Interstate standard. Machines, devices and other technical products. Versions for different climatic regions. Categories, operating conditions, storage and transportation in terms of the impact of climatic factors of the environment, Moscow (2010). 